\title{
Scope Creep and Purposeful Pivots in Developmental Evaluation
}

\author{
Suparna Roy and Michelle Searle \\ Queen's University
}

\begin{abstract}
This practice note illustrates a situation where, as program evaluators, we crept beyond the provisional boundaries set by our Developmental Evaluation (DE) goals to facilitate learning. Our DE was initially focused on one program which was being designed for online delivery in higher education. During the DE of this program, questions and themes arose which had larger organizational applicability; we were asked to help design a strategic learning session that addressed a large group of stakeholders within which existed the tiny subset of stakeholders engaged in the original DE. This practice note describes how we negotiated the emergent purposes of the DE with the need for intentional pivots within the strategic learning session to serve our intended subset of stakeholders with their project as well as stimulate evaluative thinking within the larger stakeholder group.
\end{abstract}

Keywords: capacity building, complexity theory, developmental evaluation, higher education, online learning

Résumé : La présente note sur la pratique illustre une situation où, comme évaluateurs et évaluatrices de programme, nous dépassons les limites provisoires établies par nos objectifs d'évaluation évolutive (EE) pour faciliter l'apprentissage. Notre EE portait, au départ, sur l'élaboration d'un programme postsecondaire, enseigné en ligne. Au cours de l'EE de ce programme, des questions et des thèmes d'une vaste portée organisationnelle ont été soulevés; on nous a demandé d'aider à concevoir une séance d'apprentissage stratégique destinée à un groupe d'intervenants, comprenant notamment les intervenants ayant participé à l'EE originale. La note sur la pratique décrit la façon dont nous avons négocié les objectifs émergents de l'EE, tout en tenant compte du besoin d'insérer des points décisionnels dans la séance d'apprentissage stratégique pour aider les intervenants à réaliser leur projet, de même que pour stimuler une réflexion d'évaluation au sein d'une plus vaste groupe de parties prenantes.

Mots clés : renforcement des capacités, théorie de la complexité, évaluation évolutive, études supérieures, apprentissage en ligne

A steady growth in demand for online education has resulted in an expansion of online course offerings in higher education institutions (Brinkley-Etzkorn, 2018). Universities concerned with both quality and innovation require a great deal of

Corresponding author: Suparna Roy, Coordinator of Teaching, Learning, and Innovation, Albert College, 160 Dundas Street West, Belleville, ON, K8P1A6; suparna.roy@queensu.ca 
preparation to launch these offerings (Christie \& Garrote Jurado, 2009). To help monitor the quality and innovative capacity of the team developing and offering one such suite of online courses, we were hired by an Online Distance Studies (ODS) department of an institute of higher education to conduct a Developmental Evaluation (DE) during the construction of one online program.

In contexts of programmatic innovation driven to meet social needs, the evaluation practices being adopted have more developmental purposes (Milley, Szijarto, Svensson, \& Cousins, 2018). Despite the enthusiasm for DE, there is a need for ongoing research that examines common mediating factors emerging in Des, including conflict, relationships, and time within DE contexts (Milley et al., 2018). This practice note provides a closer look at one way to approach some of these concerns within a DE. Our attempt to mitigate conflict and foster relationship-building required stepping beyond the provisional boundaries negotiated for this DE to involve a wider stakeholder audience in a purposefully crafted learning session designed to nurture collaboration and co-creation.

\section{PROGRAM CONTEXT}

In 2016, the ODS unit of a higher education institution applied for and was granted provincial funding for creating and offering an online certification program (OCP) consisting of five courses that targeted distance and on-campus undergraduate and postgraduate students. Each course already existed as a traditional classroom-based offering. The online counterparts each catered approximately 30 to 90 students. Shifting to an online context posed an interesting challenge for those involved because the courses, all multidisciplinary in nature, focused on developing an understanding of human relationships through active learning experiences. Learning outcomes not only addressed identifying, connecting, and evaluating complex problems from a variety of perspectives but also aimed to develop an awareness of personal responsibility, trust, ethical behaviour, and the need for ongoing professional development. Shifting courses of this nature to an online platform represented a significant move, spearheading the way for other institutions.

The key stakeholders (KS), including the ODS team (a subset of the larger ODS department and comprising an instructional designer, multimedia specialists, and a learning management systems specialist), along with OCP instructors, began grappling with the challenge of creating authentic online-learning experiences. To cater to both content- and interpersonal skills-based learning outcomes, the KS began developing online courses with innovative features such as gamesbased learning, synchronous sessions that allowed for discussions and debates between groups of students, and assessments that allowed students choice and autonomy. Not all instructors chose to include a final exam. Rather, the final mark could be composed of group submissions and projects that involve case analyses of current issues. Innovation was viewed by the KS as an essential criterion for successfully meeting the curricular demands as well as the needs of online audiences to ensure uptake of courses and the certificate. 


\section{CHOOSING A DEVELOPMENTAL EVALUATION APPROACH}

An evaluation was stipulated by the provincial funding agency, and the ODS team sought external evaluators to conduct a Developmental Evaluation (DE). Patton $(1994,2011)$ is credited with launching DE to support program innovation where key stakeholders are engaged in "systematic evaluative inquiry to meet the utility needs and developmental aspirations ... in a just-in-time fashion" (Lam \& Shulha, 2015 , p. 362). A foundational belief of DE is that change is a process rather than an event and therefore encourages gathering changing and multiple perspectives over time (Patton, 2011). Further, a DE moves beyond the traditional formativesummative evaluation dichotomy where classically formative evaluation supports the process of program improvement in anticipation of the summative assessment (Patton, 1996). As such (sometimes even in the absence of a stipulated summative), DE data inform continuous improvement, adaptation, and intentional changes, at times generating knowledge that stimulates conceptual shifts that may or may not be directly acted upon (Patton, 1996). Since the OCP was in its infancy and was being implemented in a complex environment, a DE provided the flexibility to capture data throughout the early implementation of some of the program's courses, with the aim of suggesting improvements and examining initial outcomes (Preskill \& Beer, 2012) to guide adaptation and change. Additionally, the emphasis on collaboration during a DE (Shulha, Whitmore, Cousins, Gilbert, \& al Hudib, 2016) matched the interactional ethos desired within the ODS team and faculty.

\section{DEVELOPMENTAL EVALUATION UNLEASHED}

We drafted up priority areas, informed by the program goals and the original proposal, which were then collaboratively refined by the ODS team and an instructor representative. Questions were clustered around two priority areas: the certification program and collaboration. Those questions under the certification program dealt with the vision of the program, course development, learning outcome alignment with intended program goals, and the student experience. Collaboration questions dealt with the resources, departmental structures and processes, and the values or practices that could influence the functionality and quality of relationships within the program.

In the early stages of the program, we conducted document analyses using an online repository of data that tracked course development, student surveys, and course quality assessments (conducted by the ODS team after an offering) for two of the five courses. We attended three course development meetings and conducted a student focus-group interview, and at the end of two semesters conducted interviews with four of the five course instructors. With each datacollection event, we presented analyzed data to the ODS team and the instructor representative during collaborative meetings and encouraged them to discuss how they wanted to respond to the findings. In one such case, the ODS team wanted to gain more informative data from the four surveys that were sent to 
students at different points during a course offering. Working collaboratively, we helped the ODS team create a template outlining the types of survey modifications that catered to the DE priority areas (such as considering instructor voice, and questions that shed light on the notoriously difficult arena of tracking students' transferable skills development). The ODS team was so pleased with the survey modification guide that they implemented it across courses beyond the OCP in focus.

\section{SCOPE CREEP}

Scope creep is prominent in project management literature. The scope of a project includes the objectives, time frame, assumptions, and limitations (Groff \& Jones, 2012). Scope creep, on the other hand, refers to the changes made to the original project goals, often to satisfy stakeholders, and sometimes to the point where the result bears little resemblance to the former agreement (Mikkelsen, 2018).

From a business perspective, it is tempting to respond to emerging information as a project evolves, but too many changes without formal analysis can lead to gross overestimations of benefits, delays, greater costs, management difficulties, and negative unintended consequences (Kendrick, 2015). On the other hand, successful scope creep can occur when proper analysis is conducted to provide evidence that benefits could outweigh the costs and lost time. Examples of both successful and not so successful scope creep are available in the literature (e.g., Gary, 2005; Goldstein, Bergman, \& Maier, 2013; Jonker \& Meehan, 2008; McElhinney \& Proctor, 2005).

In this DE context, the ODS departmental leaders had a desire that the DE investment required for this program could positively influence actions in other ODS departmental areas. By trying to balance their desires for broader implications, such as that of conducting a strategic learning session for the entire ODS departmental staff, and meet the programmatic evaluation requirements mandated by funders, our evaluation boundaries expanded, or crept, beyond the original scope of the evaluation. It may be that the ODS departmental leaders wished to leverage our skills as evaluators to an additional service to benefit the greater department. However, we began thinking of pivoting the purpose of the strategic learning session toward "spreading the evaluation expertise" by offering other ODS departmental staff additional resources, such as professional learning and feedback mechanisms, that might positively influence all program areas (including the OCP) and thereby lead to overall system growth.

\section{EXAMINING SCOPE CREEP IN A DEVELOPMENTAL EVALUATION}

DE contexts naturally encounter scope-creep situations because their "main function [is] to facilitate development and adaptation" (Milley et al., 2018, p. 240). Kendrick $(2015$, p. 52$)$ notes that complex projects are especially susceptible to scope creep because "new opportunities, interesting ideas, undiscovered alternatives, 
and a wealth of other information emerges [sic] as the project progresses." A DE's scope and mission are to be responsive to the complex systems (Milley et al., 2018) - where social systems interact to produce creative and innovative products. Adaptation can promote ongoing learning as programs are being designed and innovation is fostered (Patton 1994, 2011).

Purposeful creeping in a DE includes a careful analysis of the nested systems. The scope of a DE of a program such as the OCP should initially be limited to levels containing "only the most basic and critical influences and their relationships," based on the pragmatic point of manageability (Patton, 2011, p. 120). Figure 1 illustrates the nested levels of our system. Our provisional boundary, therefore, encompassed the aforementioned DE priority areas to service the KS while being mindful of external influences. Conducting a strategic learning session for the ODS department at first seemed like an additional service. However, we thought that if our DE scope embraced a wider system level to increase overall evaluative capacity while favouring the DE priorities (that were not so different from those of the department), then fruitful outcomes might follow. In other words, rather than just consider the influence and relationships of the ODS department level on the OCP and ODS team levels, our DE scope expanded to involve the former and attend to their contribution within the collaborative aspect of the OCP DE priority areas.

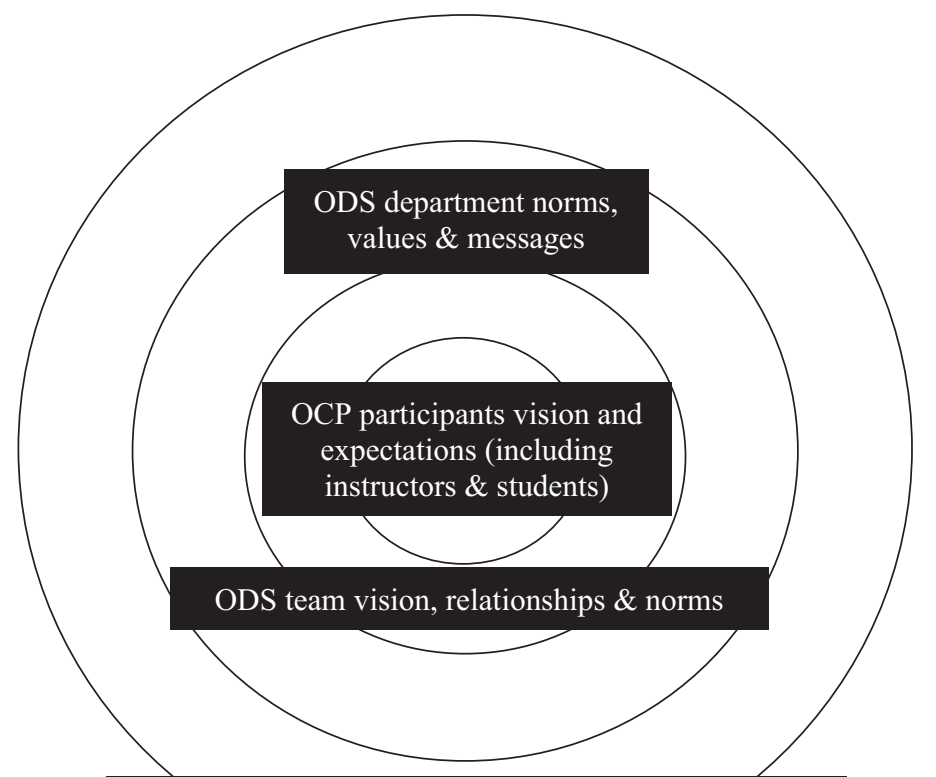

Societal teaching \& Learning norms \& expectations

Figure 1. Levels of the OCP developmental inquiry (adapted from Patton, 2011, p. 120) 
We recognized that, with a systems lens, the ODS department as a whole, and the multiple program teams within it, might be able to share responsibility for some of the supports identified during the DE (i.e., online course development structures and faculty training processes). We recognized that strong meaningful relationships, shared goals, and unified voices at a systems level could streamline resource allocation and desired future improvements. For example, initially there was concern that providing additional resources, in the form of external evaluation experts, to one ODS program team may create an imbalance or conflict at the larger system level. We felt that involving the whole department in a strategic learning session might allow others to feel included, create a facilitated space for discussion, continue to build trusting relationships, and inject evaluative thinking into the wider system.

Scope creep could enable further co-creation and collaboration, which have already been identified as central to the DE approach (Patton, McKegg, \& Wehipeihana, 2015; Shulha et al., 2016). In a context where innovation is necessary, we speculated that increasing participation across a system may contribute to growth in innovation because of the opportunity to engage multiple perspectives, agitate new ideas, seek out role clarification, and enhance a sense of how individual roles are interacting for the betterment of the system as a whole. We wondered if enabling DE scope creep, supervised by purposeful pivots, could contribute to a renewed or refined understanding of departmental objectives, which might therefore lead to more successful collaborative journeys within the ODS team.

\section{PURPOSEFUL PIVOTS}

Document analyses, observations of course development meetings, instructor interviews, and focus groups with students who took early online offerings of some of the courses prompted questions about online learning resources, student perceptions of teaching and assessment, and the overall timeline for the many phases of developing a new online program. While these questions were developed specifically from the DE process, we recognized that these ideas were at play elsewhere within other ODS teams dedicated to other online courses.

Working with the stakeholders involved in the DE, we designed a four-hour strategic learning session for an ODS department of 28 people. The strategic learning session was intended to be beneficial for the entire organization and leave scope for alignment with the DE priority areas. We use the phrase "purposeful pivots" to describe how we tried to create strategic learning session activities that could serve these dual purposes-that of the department and that of the DE. In other words, we were conscientiously creeping out of our provisional boundary while incorporating markers within that space to pivot back to our given goals. The three main activities are summarized in Table 1, along with how they link to the DE philosophy as well as the DE priority areas for this evaluation. 


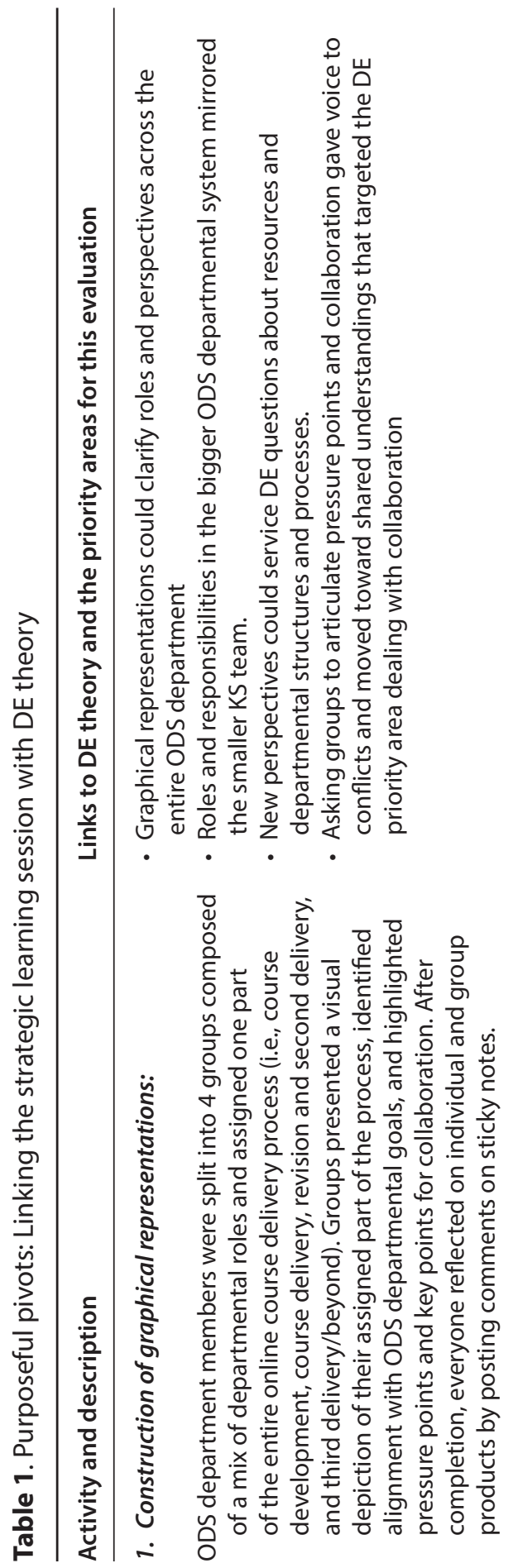

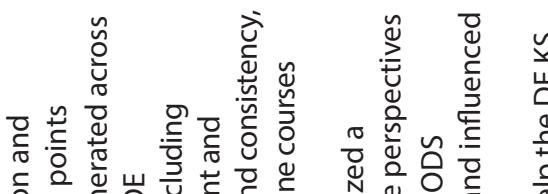

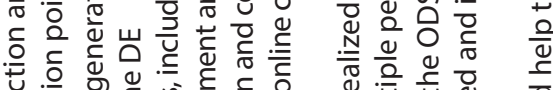

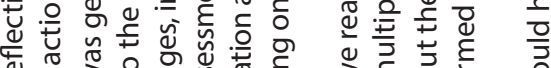

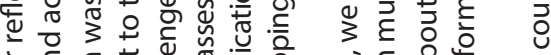

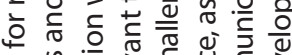

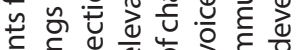

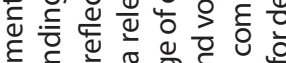

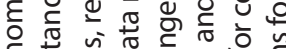

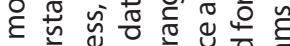

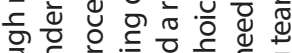

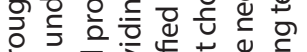

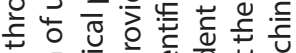

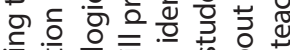

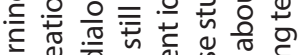

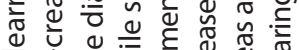

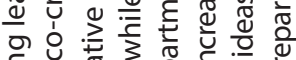

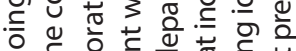

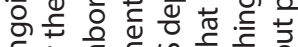

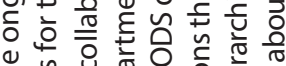
ชั

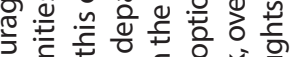
얼 至

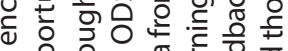

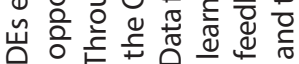

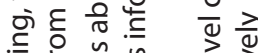

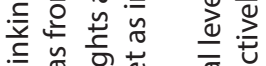

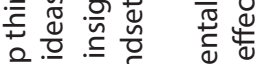

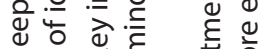

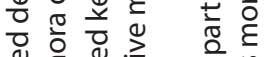

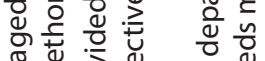
응 응

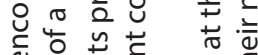

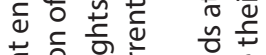

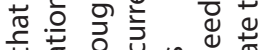

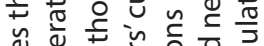

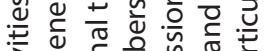

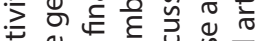

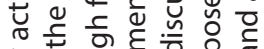

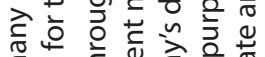

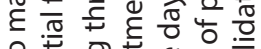

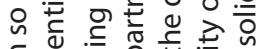

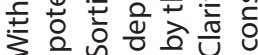
-

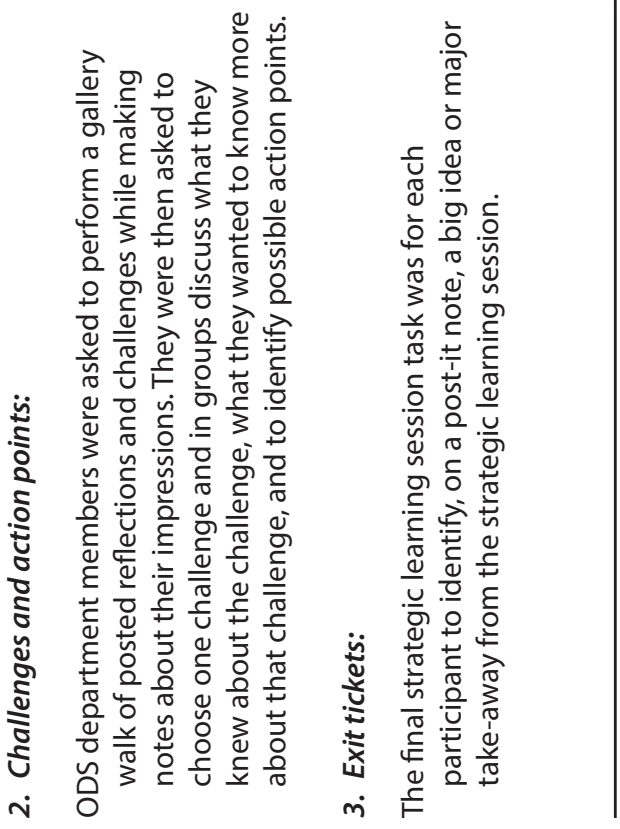




\section{DISCOVERIES FROM PRACTICE}

Good practice in the world of evaluation competency dictates the necessity of being a reflective practitioner to ensure impartial and ethical reasoning aligned with professional standards as a way to ultimately enhance evaluative practice (CES, 2010). In fact, it was during our reflection upon the anticipated and unanticipated consequences of the strategic learning session that we began to appreciate the DE's scope creep and how we implemented purposeful pivots to align with good evaluation practice. Below we describe the anticipated consequences, in other words, those results that the purposeful pivots were expected to yield. In contrast, the unanticipated consequences reveal some assumptions we had about the ODS department prior to the session. Since the strategic learning session was pivoted to address the DE priority areas, all of the examples below illustrate how the participants ended up being affected by the process itself (rather than evaluation findings). It might be interesting to note that this type of outcome is also known as process use (Patton, 2008), another feature integral to the ethos of developmental evaluations.

\section{Anticipated consequences}

\section{Role clarification and relationship-building}

Since the activity groups consisted of people with different roles working together, each member had a voice to showcase their responsibilities and become more familiar with the work experienced by their colleagues at various points of the process (and why, at times, pressure was greater for some than others). During the strategic learning session there was evidence that ODS department participants came to new realizations. We heard comments like "Oh, I didn't realize that you had to do that too" or "Wow, now I see what this part of the process involves!" It may be that this greater familiarity stimulated greater appreciation for colleagues and an awareness of the types of talents that each member brought to the table. For most members, this was the first time that they could stand back to study the ODS system in its entirety. Mutual appreciation added to the air of inclusivity. Many participants asked for another opportunity to come together and revisit the graphical representation at a future session. The exercise of creating these graphical representations built a sense of community pride in knowing that each member was a necessary and valued component of a complex system.

\section{Focus on innovation}

From data generated as part of the DE, we knew that being innovative, on both fronts of generating authentic student experiences online and improving communication pathways during the course development process, was a key focus. During the strategic learning session we confirmed that others in the ODS department also highly valued innovation. During the activities many ideas were generated about student learning and course development technological aids, as well as novel approaches to tackle some of the pressure points and issues that emerged from the graphical representations. For example, a ticketing system idea was proposed to 
help the learning management systems specialist cope with the deluge of student emails that would saturate the inbox during certain points of course delivery. The strategic learning session provided a time for successes from one portion of ODS work to be better understood by others working on a different part.

\section{Alignment with data from the $D E$}

During the DE, ideas and questions that required attention had emerged from multiple data sources. For example, instructor interview data identified a need and desire for greater training about online learning prior to starting course design. Although these data were not presented at the strategic learning session, the ODS department strongly corroborated this action point. Several ideas around the need for instructor induction processes were reiterated and a possible plan of creating online modules to provide learning about and experience in online course development was born. The strategic learning session created the type of convergent data that the KS felt necessary to have in order to move it forward into an area earmarked in the DE for immediate attention and change.

\section{Unanticipated consequences}

\section{Valuing togetherness}

There was an air of celebration from the moment the ODS department members entered the strategic learning session space. We heard a lot of laughter and felt a readiness to be participative and learn. During the session, we learned that the department had not had a chance to be together like this for a very long time, and the novelty of the impending experience added to the air of excitement. They relished "breaking free" of separate desk/office spaces and meeting faceto-face-so much so that by the end of the day they had committed to creating more opportunities to meet together (even voicing the need to collectively work in one space). As evaluators we marveled at the degree of enthusiasm that never seemed to wane. In fact, the enthusiasm seemed to build with each collaborative opportunity. The intensity of it all signified that perhaps such a strategic learning session was needed more than we had anticipated.

\section{Emergence of focused intentions}

With so many participants, we did not think that clear actions for the future would be established. However, the exit tickets, which distilled core ideas from the department, clearly articulated thematic areas for future action. The top two themes that emerged were stronger communication among ODS department members, to be possibly realized through an online platform (e.g., SLACK), and more opportunities to connect socially and to work collaboratively.

\section{CONCLUDING THOUGHTS}

Scope creep during a DE can be leveraged to contribute to programmatic learning when purposeful pivots, such as the ODS strategic learning session, have beneficial consequences. In our context, the strategic learning session was perhaps more 
efficient and productive because areas affecting the KS in the DE were embedded at the ODS departmental level, and the larger level necessarily affects a nested level. With consequences that included fostering communication, clarifying roles and responsibilities, building community, and generating new ideas, DE scope creep could positively influence the DE.

There are, however, challenges with DE scope creep. Although DE is intended as a responsive and generative approach, expectations for both the evaluation team and the KS might grow as a result of project creep or data generated from additional activities. We discovered that some KS might feel additional or weighty responsibilities to implement changes requested by generated data and that this can create issues associated with feasibility. Overall, a plan is needed to communicate lines that demarcate data that are both relevant and not as relevant to the DE with action ideas for both. If suggestions from the ODS department are ignored and momentum dies at the outer system level, then it has the potential to affect the levels nested within, and consequently DE scope creep could have an unintended negative consequence on the DE.

Having been exposed to DE scope creep within this DE context, many evaluators might be able to think back to previous experiences and filter out moments when their own evaluation boundaries threatened to creep or were allowed to do so with a leash of purposeful pivots. The choice to creep comes down to a set of decisions that involve time, resources, and stakeholder relationships, curiously similar to those that are mediating factors in DEs (Milley et al., 2018). Questions to ask in the instance of project creep include the following: Do the costs outweigh the benefits? Have we taken the time to conduct a careful analysis or are we bending to a stakeholder whim/pressure? Finally, is the stakeholder with the greatest power willing to acknowledge, take the risk, and invest the time to work with the extra generated data?

\section{REFERENCES}

Brinkley-Etzkorn, K. E. (2018). Learning to teach online: Measuring the influence of faculty development training on teaching effectiveness through a TPACK lens. The Internet and Higher Education, 38, 28-35. https://doi.org/10.1016/j.iheduc.2018.04.004

Canadian Evaluation Society (CES). (2010). Competencies for Canadian evaluation practice. Retrieved from https://evaluationcanada.ca/txt/2_competencies_cdn_evaluation_ practice.pdf

Christie, M., \& Garrote Jurado, R. (2009). Barriers to innovation in online pedagogy. European Journal of Engineering Education, 34(3), 273-279. https://doi.org/10. 1080/03043790903038841

Gary, L. (2005). Will project creep cost you-or create value? Harvard Management Update, 10(1), 3-5.

Goldstein, H., Bergman, E. M., \& Maier, G. (2013). University mission creep? Comparing EU and US faculty views of university involvement in regional economic 
development and commercialization. Annals of Regional Science, 50(2), 453-477. https://doi.org/10.1007/s00168-012-0513-5

Groff, T., \& Jones, T. (2012). Introduction to knowledge management. New York, NY: Routledge.

Jonker, K., \& Meehan, W. F., III (2008). Curbing mission creep. Stanford Social Innovation Review, 6(1), 60-65.

Kendrick, T. (2015). Identifying and managing project risk: Essential tools for failure-proofing your project. New York, NY: AMACOM.

Lam, C. Y., \& Shulha, L. M. (2015). Insights on using developmental evaluation for innovating: A case study on the cocreation of an innovative program. American Journal of Evaluation, 36(3), 358-374. https://doi.org/10.1177/1098214014542100

McElhinney, D., \& Proctor, T. (2005). Concept of entrapment and decision-making. Management Decision, 43(2), 189-202. https://doi.org/10.1108/00251740510581911

Mikkelsen, M. F. (2018). Projects, success, and complexity. International Project Management Association Research Conference 2017. Sydney, Australia: UTS ePRESS.

Milley, P., Szijarto, B., Svensson, K., \& Cousins, J. B. (2018). The evaluation of social innovation: A review and integration of the current empirical knowledge base. Evaluation, 24(2), 237-258. https://doi.org/10.1177/1356389018763242

Patton, M. Q. (1994). Developmental evaluation. American Journal of Evaluation, 15(3), 311-319. https://doi.org/10.1177/109821409401500312

Patton, M. Q. (1996). A world larger than formative and summative. Evaluation Practice, 17(2), 131-144. https://doi.org/10.1177/109821409601700205

Patton, M. Q. (2008). Utilization-focused evaluation (4th ed.). Thousand Oaks, CA: Sage Publications.

Patton, M. Q. (2011). Developmental evaluation: Applying complexity concepts to enhance innovation and use. New York, NY: Guilford Press.

Patton, M. Q., McKegg, K., \& Wehipeihana, N. (2015). Developmental evaluation exemplars: Principles in practice. New York, NY: The Guilford Press.

Preskill, H., \& Beer, T. (2012). Evaluating social innovation. Washington, DC: FSG and the Centre for Evaluation Innovation. Retrieved from http://www.evaluationinnovation. org/sites/default/files/EvaluatingSocialInnovation.pdf

Shulha, L. M., Whitmore, E., Cousins, J. B., Gilbert, N., \& al Hudib, H. (2016). Introducing evidence-based principles to guide collaborative approaches to evaluation: Results of an empirical process. American Journal of Evaluation, 37(2), 193-215. https://doi. org/10.1177/1098214015615230

\section{AUTHOR INFORMATION}

Suparna Roy is the Coordinator of Teaching, Learning, and Innovation at Albert College, a K-12 Canadian independent chool. In addition to bringing educational research to teachers to help them progress toward their pedagogical goals, Suparna actively implements developmental evaluation techniques to further whole-school professional learning. She is 
also pursuing her research passion of cultivating core values within learning communities through service- and inquiry-based pedagogies.

Michelle Searle is an assistant professor of educational evaluation in the Faculty of Education at Queen's University and a Credentialed Evaluator (CES). Her research focuses on increasing the usefulness of program evaluation through a focus on collaborative evaluation approaches and innovative forms of knowledge dissemination that enhance capacity within organizations. 